\title{
Canadian baby boomers shirk safe sex
}

Published at www.cmaj.ca on Nov. 16

$\mathrm{W}$ ith little sexual health information targeted toward aging baby boomers, Canada's free love generation remains "woefully ignorant" that they are at risk of contracting sexually transmitted infections (STIs), experts say.

Many boomers are shirking the safe sex practices they taught their children, largely under the misconception that their age somehow exempts them from contracting STIs, such as hepatitis B, says Dr. Morris Sherman, chairman of the Canadian Liver Foundation.

According to a recent online survey conducted by the foundation, $70 \%$ of boomers with children said they tell their kids to use protection during sex, but $16 \%$ admit they don't always practise what they preach (www.liver.ca /Liver_News/livernews10051001.aspx).

"When you're 45 or 50, the fear of pregnancy is no longer there, so many people think, 'I'm not gallivanting around having sex with large numbers of people, so my risk of disease is low.' That's just not the case," says Sherman. "STIs are on the rise among baby boomers, just as we're seeing a decrease in condom use."

More than half of survey respondents weren't concerned about contracting STIs, while one in five said they don't use condoms as frequently, since pregnancy is less of a concern.

"It's not because all boomers are married and monogamous, either," says Alexander McKay, research coordinator for the Sex Information and Education Council of Canada.

Many boomers are returning to the dating scene following divorce or the death of a spouse, McKay says, while relaxed social mores mean even married boomers may have multiple partners (with or without their spouse's knowledge).

"If you examine condom use from teenage years onwards, you find a very consistent decline in use with age," he

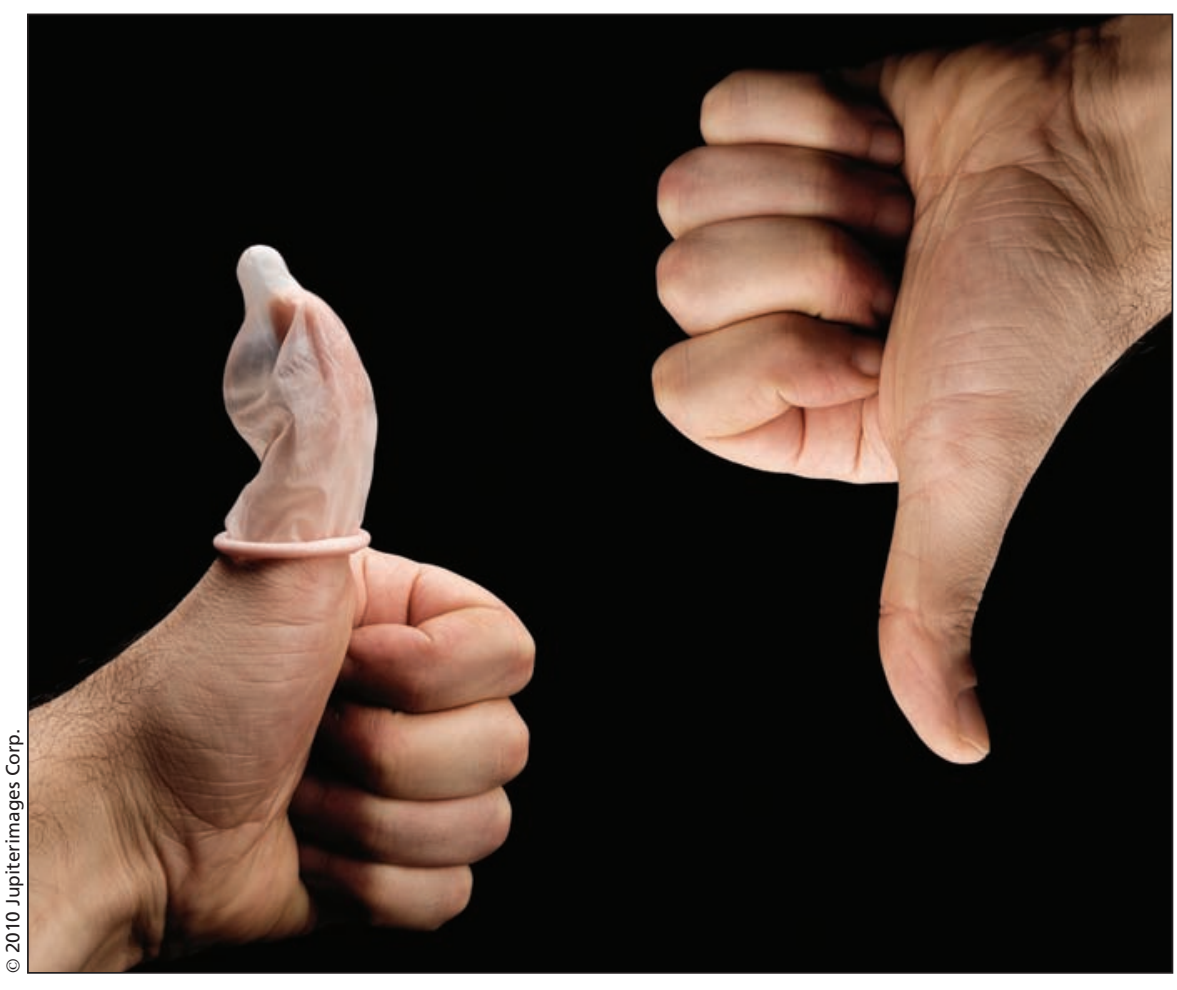

Nearly a third of unmarried boomers surveyed by the Sex Information and Education Council of Canada admitted to having unprotected sex with a new partner since turning 40.

says. "Even among people who are single and have multiple partners in a year."

Nearly a third of unmarried boomers surveyed admitted to having unprotected sex with a new partner since turning 40 .

Male boomers were also found to be more open to risky dating habits than their female counterparts. Some $40 \%$ of men said they were more open to a one-night stand since turning 40, compared to only $5 \%$ of women. Likewise, $37 \%$ of men said they were looking for a "good time" rather than a serious relationship now that they were older, compared to $18 \%$ of women.

"Baby boomers are transitioning from one relationship to another and are having unprotected sex with multiple partners, but there's a persistent belief that STIs are a young person's problem," says McKay.

While young people continue to account for the highest reported rates of chlamydia, gonorrhea, and syphilis, the rate among older adults has risen in recent years, according to the Public Health Agency of Canada. Notably, men over the age of 60 have experienced a "dramatic" rise in the rate of reported cases of gonorrhea since 1999 (www.phac-aspc.gc.ca/std-mts/report/sti -its2008/index-eng.php).

"And that may not even come close to representing the true burden, because you can't report a positive result if a person doesn't get tested," says McKay.

Many boomers don't know that most cases of STIs are asymptomatic, he says. That means they may not bother getting screened or asking new partners to be screened so long as they seem healthy.

While boomers are aware of the health risks posed by HIV/AIDS, McKay says the associated health risks of contracting other STIs are taken less seriously. 
Hepatitis A, B and C infections, for example, are "not on the radar at all," says Sherman. Only one in four boomers surveyed knew hepatitis could cause extreme fatigue, jaundice or death.

"A lot of that stems from the limited sex education baby boomers received in their youth," says McKay, citing the traditional emphasis placed on condoms as being primarily a means for preventing pregnancy, rather than disease. "It's not that education programs we provide youth today are perfect by any stretch of the imagination, but today's generation of youth tend to be better informed around sexual health than their baby boomer predecessors."

It's also more difficult to reach boomers with sexual health programs, he says. "We're accustomed to reaching youth with information about the importance of condom use and that's facilitated through programs in high schools and college campuses. Even for seniors, there's a point of contact in retirement communities or other dedicated programming."

South of the border, rising STI rates among seniors have prompted sex educators in New York City, New York, and San Francisco, California, to target sexual health classes to retirement communities. But in Canada there's a dearth of sexual health information, let alone classes, dedicated to more elderly generations. "Even the pictures we associate with sexual education campaigns almost always depict young people. They don't depict grey hairs," says Sherman.

McKay says social media campaigns could be an effective tool for disseminating the message. The Society of Obstetricians and Gynaecologists of Canada, for example, has included a section on aging and sex on their Sexuality andU.ca website (http://www.sexuality andu.ca/home_e.aspx).

An effective campaign, though, would require more engagement than just posting statistics online as many boomers may not realize they need a refresher course on sexual health, McKay adds.

Family doctors could play a more active role, he says. "Physicians are responsible for so many different aspects of a patient's health that sexuality issues, particularly with adult patients, can sometimes fall to the wayside. But they're ideally placed to address these issues, not least because baby boomers lend a lot of credibility to their family doctors, and it works with the way they have traditionally received sex education."

Given that health care costs associated with boomers are exploding, it's in society's interest to provide them better sexual health education, McKay argues. "Otherwise, the taxpayers will end up paying for the negative health outcomes of leaving this unchecked." — Lauren Vogel, CMAJ

DOI:10.1503/cmaj.109-3729 